\title{
COMUNICAÇÃO
}

\section{ASPECTOS SANITÁRIOS DO CULTIVO DA ALFACE AMERICANA, IRRIGADA COM ÁGUAS RECPTORAS DE EFLUENTES URBANOS}

\author{
Sanitary aspects of lectucce (Lactuca sativa L.) culture irrigated with receiving \\ waters of urban effluent
}

\author{
Guilherme Augusto Biscaro ${ }^{1}$, Andréa Bogatti Guimarães-Tomazela ${ }^{2}$ \\ Raimundo Leite $\mathrm{Cruz}^{3}$, Marcelo Domingos Chamma Lopes ${ }^{4}$
}

\begin{abstract}
RESUMO
Avaliou-se a influência da disposição de mangueiras gotejadoras nos canteiros e a injeção ou não de cloro na água de irrigação, nas condições sanitárias do solo e da alface americana irrigada (Lactuca sativa L.) com águas receptoras de efluentes urbanos. Foram realizadas análises microbiológicas de amostras de água do solo e da alface, no decorrer de todo o ciclo de cultivo. Objetivou-se determinar a possível existência de Salmonella spp. e de formas evolutivas de parasitos humanos e a quantidade de coliformes fecais, em pontos e épocas diferentes do experimento, impedindo assim o consumo da alface. Os resultados não indicaram a presença dos dois primeiros em nenhuma das amostras, mas sim de parasitos não humanos (nematóides) de vida livre no solo. Em relação à quantidade de coliformes fecais (NMP ml-1), o valor encontrado na cultura atende às exigências da Secretaria de Vigilância Sanitária do Ministério da Saúde brasileiro, porém a presença dos nematóides em quantidades superiores ao permitido pela Organização Mundial de Saúde (OMS) inviabiliza o seu consumo.
\end{abstract}

Termos para indexação: Nematóides, Salmonella, coliformes fecais, gotejamento.

\begin{abstract}
One evaluated the influence of drip tape arrangement and the use of chloride in the irrigation water, on soil sanitary conditions and growing lettuce (Lactuca sativa L.), irrigated with receiving urban waters. Water, soil and lettuce microbiological analyses were performed during crop cycle. The objective was to determine the presence of Salmonella spp., evolutive forms of human parasites and the amount of fecal coliforms in different locations and time, avoiding the lettuce consumption. Although results did not indicate the presence of Salmonella spp. and evolutive forms of human parasites in none of the samples but non human parasites (nematodes) of free life in soil. Total fecal coliforms count (NMP ml-1) met is according to the Brazilian Ministry of Health, Secretary of Health Surveillance requirements. Yet, the lettuce was not good for human consumption as the nematode presence was above the World Health Organization (WHO) guidelines.
\end{abstract}

Index terms: Nematode, Salmonella, fecal coliforms, drip irrigation.

(Recebido em 9 de março de 2006 e aprovado em 12 de junho de 2007)

O desenvolvimento de pesquisas que possibilitem adotar estratégias para maximizar a utilização de águas residuárias em áreas agrícolas, tornou-se imprescindível uma vez que parte considerável da água disponível é utilizada para irrigação de culturas de interesse comercial O uso agrícola de águas residuárias é viável desde que sejam adotadas técnicas apropriadas para o controle de seus componentes em longo prazo (HARUVY, 1997).
De acordo com Lopez-Flores et al. (2003), é difícil identificar os principais componentes poluidores das águas e suas concentrações estando eles relacionados com as atividades predominantes nos locais. Observa-se que, em áreas industriais e urbanas, a poluição é gerada na maior parte por metais pesados e hidrocarbonetos aromáticos e alifáticos enquanto que em áreas agrícolas há maiores percentuais de nutrientes, herbicidas e inseticidas. Os corpos

\footnotetext{
${ }^{1}$ Doutor, Professor Adjunto - Departamento de Agronomia - Unidade Universitária de CassilândiaUUC - Universidade Estadual de Mato Grosso do Sul/UEMS - Rodovia MS 306, KM 6.4 - Zona Rural - 79540-000 - Cassilândia, MS - gbiscaro@hotmail.com ${ }^{2}$ Doutora, Professora - Campus Experimental do Litoral Paulista - Universidade Estadual Paulista Júlio de Mesquita Filho/UNESP Praça Infante Dom Henrique, s/n - Parque Bitaru - 11330-900 - São Vicente, SP - andreatomazela@csv.unesp.br ${ }^{3}$ Doutor, Professor Adjunto - Departamento de Engenharia Rural/DER - Universidade Estadual Paulista Júlio de Mesquita Filho/UNESP Cx. P. 237 - 18603-970 - Botucatu, SP - cruz@fca.unesp.br

${ }^{4}$ Doutor, Professor - Departamento de Agronomia - Universidade Estadual Paulista Júlio de Mesquita Filho/UNESP - Unidade Diferenciada de Registro - Rua Tamekishi Takano, 5 - Centro - 11900-000 - Registro, SP - lopesmdc@ registro.unesp.br
} 
d'água poluídos por esgotos domésticos apresentam valores do parâmetro de condutividade elétrica, diretamente relacionados com a quantidade de matéria orgânica de origem alimentar e fecal e de resíduos em geral, presentes na água. Todo esse material irá incorporar sais aos corpos d'água(BLUNDI, 1988).

Os primeiros padrões adotados para irrigação com águas residuárias foram estabelecidos na Califórnia em 1918, os quais, entre outras normas, proibiam a utilização de efluentes brutos e de tanques sépticos para a irrigação de vegetais ingeridos crus (BASTOS \& MARA, 1993). A Califórnia tem um dos padrões mais rigorosos do mundo: 2,2 coliformes/100 ml para culturas consumidas cruas (LÉON \& CAVALLINI, 1996). Castro de Esparza \& Sáenz (1990) sugerem que, para que não se encontre Salmonella spp. em hortaliças irrigadas com águas residuárias, o limite de coliformes fecais na água de irrigação deve ser de $10^{4}$ organismos por $100 \mathrm{ml}$. Vários estudos foram idealizados para se ter índices aceitáveis, até que em 1985, no documento conhecido como Relatório de Engelberg, a Organização Mundial da Saúde (OMS) passou a recomendar um padrão de qualidade bacteriológica de $10^{3}$ coliformes fecais por $100 \mathrm{ml}$ para irrigação, sem restrições (SILVA, 2003).

Desde a publicação dos critérios da OMS, diversos estudos permitiram de certa forma, o respaldo dos padrões estabelecidos. No Brasil, a resolução n. ${ }^{\circ}$ 20/86 do Conselho Nacional do Meio Ambiente (CONAMA, 1998) estabelece que, para a irrigação de hortaliças que são consumidas cruas e de plantas frutíferas que se desenvolvem rente ao solo, as águas não devem ser poluídas com excrementos humanos.

Os organismos patogênicos apresentam os seguintes tempos de sobrevivência em produtos agrícolas: Salmonella spp. - 10 a 53 dias nas raízes, 1 a 40 dias em folhas vegetais em até dois dias em frutos; Shigella spp. dois a sete dias em folhas e até seis dias em frutos; Enterovírus - 15 a 60 dias em raízes e em folhas; Ascaris spp. (ovos) - até 35 dias em folhas e Entamoeba histolytica - até três dias em folhas (MELO, 1978).

Maciel (1984) cita que o ciclo de vida da maioria dos helmintos ocorre de forma direta, envolvendo uma fase parasitária, representada pela população deles no hospedeiro e outra não parasitária, ocorrendo no meio externo. O alojamento no hospedeiro é responsável pela taxa de contaminação ambiental, enquanto o do meio externo condiciona a taxa de infecção dos hospedeiros. Os ovos e as larvas de nematóides são resistentes ao estresse do meio ambiente e podem sobreviver aos procedimentos usuais de desinfecção. Os ovos de helmintos, porém, são removidos por processos utilizados na prática do tratamento dos esgotos, como a sedimentação, a filtração e os sistemas de lagoa de estabilização.

Baseando-se na importância do reaproveitamento agrícola de águas servidas e nas exigências legais para exercer tal atividade, objetivou-se neste trabalho, estudar os aspectos sanitários da alface irrigada por gotejamento com águas receptoras de efluentes urbanos do Ribeirão Lavapés, no município de Botucatu, São Paulo. Para isso, verificou-se o efeito da disposição das mangueiras gotejadoras sobre os canteiros e a influência da injeção de hipoclorito na tubulação, nas condições sanitárias da cultura.

O experimento foi conduzido de abril a maio de 2002 , em uma estação experimental ( $\left.22^{\circ} 55^{\prime} \mathrm{S}, 48^{\circ} 26^{\prime} \mathrm{W}\right)$, instalada na Faculdade de Ciências Agronômicas da UNESP, Campus de Botucatu-SP. O clima do município é classificado segundo ao sistema Köppen como Cwa: clima quente (mesotérmico), com chuvas no verão e seca no inverno, sendo a temperatura média do mês mais quente superior a $22^{\circ} \mathrm{C}$ (CUNHA et al., 1999).

O Ribeirão Lavapés foi a fonte d'água abastecedora do sistema de irrigação estudado, e é, segundo Conte (1992), receptor de todo esgoto sanitário da cidade de Botucatu e também das águas do Rio Pardo (afluente da margem direita do Rio Paranapanema). A bacia hidrográfica que inclui esse ribeirão apresenta uma descarga média estimada de $0,7 \mathrm{~m}^{3} \mathrm{~s}^{-1}$, correspondendo a uma produção diária de $60480 \mathrm{~m}^{3}$, ocupando uma área de $41 \mathrm{~km}^{2}$, com 47,5\% desta extensão em zona urbana (LEOPOLDO, 1989).

O sistema de irrigação utilizado foi do tipo localizado por gotejamento, cujas mangueiras gotejadoras possuíam espessura de $200 \mathrm{~m}$ e espaçamento de $0,10 \mathrm{~m}$ entre emissores. A cultura estudada foi a alface americana (Lactuca sativa L.), cv. 'Tainá', com espaçamento de $30 \times 40 \mathrm{~cm}$.

$\mathrm{O}$ experimento utilizou um delineamento inteiramente casualizado (DIC), com esquema fatorial $2 \times 2$, sendo composto por quatro tratamentos (T1, T2, T3 e T4) e três repetições cada. Foi avaliada a presença ou não de Salmonella spp. e formas evolutivas de parasitos humanos (cistos de protozoários e ovos de helmintos) e a quantidade de coliformes fecais em amostras de água de irrigação, do solo dos canteiros e da cultura de tratamentos que foram submetidas a diferentes disposições das mangueiras gotejadoras sobre os canteiros (na superfície do solo ou subsuperficialmente, a uma profundidade de $0,05 \mathrm{~m}$ a 0,07 m) e a injeção ou não de cloro na água de irrigação, antes do transplante das mudas (na dosagem de $40 \mathrm{mg} \mathrm{dm}^{-3}$, durante 40 minutos). Apresenta-se na Tabela 1 a composição de cada tratamento avaliado. 
Tabela 1 - Composição de cada tratamento avaliado.

\begin{tabular}{ccc}
\hline Tratamento & $\begin{array}{c}\text { Disposição das mangueiras } \\
\text { sobre os canteiros }\end{array}$ & $\begin{array}{c}\text { Aplicação de cloro } \\
\text { (antes do transplante das mudas) }\end{array}$ \\
\hline T1 & Subsuperfical & Sim \\
T2 & Sobre a superfície do solo & Sim \\
T3 & Subsuperficial & Não \\
T4 & Sobre a superfície do solo & Não \\
\hline
\end{tabular}

As amostras de solo e da alface foram coletadas após 24 horas da última irrigação e as de água no momento da irrigação, em todas as semanas do ciclo de cultivo da cultura. As amostras da água do Ribeirão Lavapés foram coletadas a uma profundidade de $0,50 \mathrm{~m}$ e as da água de irrigação no final das mangueiras gotejadoras, junto às válvulas de final de linha. Coletaram-se quatro amostras de cada item e realizou-se a média simples dos valores observados.

Para a detecção do número mais provável (NMP) de coliformes fecais, utilizou-se a metodologia proposta por Kornacki \& Johnson (2001), e para Salmonella spp. a de Downes \& Ito (2001). As análises parasitológicas realizadas foram do tipo qualitativo, utilizando o método de Faust e a técnica de Hoffman, descritas por Neves (2000) e Rey (1991).

As análises da presença de coliformes fecais nas amostras de solo, da água e da alface foram realizadas através do teste Kruskal-Wallis, pelo programa computacional STATISTICA for Windows, Release 4.2. Esse é um teste não-paramétrico, não requer que as amostras apresentem uma distribuição normal da população avaliada e com variâncias iguais. Segundo Picaró \& Perloiro (2005), o teste Kruskal-Wallis consiste numa alternativa não paramétrica à ANOVAONE-WAY, e é utilizado quando os grupos estudados não apresentam uma distribuição normal e não se verifica uma homogeneidade de variâncias em todos os grupos, que é o caso desse experimento.

O teste de Kruskal-Wallis já foi comparado com outros testes não-paramétricos e com o teste de F por Leal \& Penteado (1994). Os autores estudaram a validade do teste $\mathrm{F}$ e a eficiência de vários testes não-paramétricos no estudo de parâmetros ligados à nodulação em soja (Glycine $\max (\mathrm{L}$.$) Merrill), nas seguintes combinações: teste F e$ Kruskal-Wallis (delineamento inteiramente casualizado); teste F, Quade \& Friedman (blocos ao acaso); teste F, Bennett \& Zimmermann (quadrado latino), todos com quatro combinações de tratamentos e repetições. Os parâmetros estudados foram: número de nódulos, peso seco de nódulos e peso seco da parte aérea. O estudo da eficiência de cada teste foi feito através de 1.000 simulações para cada caso, usando-se dados oriundos de um ensaio de uniformidade com 900 parcelas. Os resultados obtidos mostram que os parâmetros ligados à nodulação não são, normalmente, distribuídos, e suas distribuições diferem de qualquer outra distribuição padronizada. O teste $\mathrm{F}$ se mostrou robusto e com um bom poder para analisar esse tipo de experimento. Os testes de Kruskal-Wallis, Quade \& Zimmermnann mostraram praticamente a mesma eficiência que o teste F; já o teste de Bennett se mostrou superior. O teste de Friedman não se mostrou válido.

Na caracterização físico-química da água do Ribeirão Lavapés encontraram-se as seguintes concentrações médias de nutrientes $\left(\mathrm{mg} \mathrm{L}^{-1}\right)$ : N $(43,90 \pm$ $3,19), \mathrm{K}(5,36 \pm 1,97), \mathrm{Ca}(5,72 \pm 1,63), \mathrm{Mg}(2,31 \pm 0,64), \mathrm{Cu}$ $(0,01 \pm 0,01), \mathrm{Fe}(0,46 \pm 0,40), \mathrm{Mn}(0,07 \pm 0,10), \mathrm{Zn}(0,01 \pm$ $0,01)$. Os valores de $\mathrm{pH}$ foram de $6,15 \pm 0,22$ e de condutividade elétrica $\left(\mathrm{mS} \mathrm{cm}^{-1}\right)$ de 181,67 $\pm 12,86$.

Parte dos resultados apresentou alta variabilidade pelo fato do ribeirão receber carga poluidora de esgotos sanitários não tratados com composição diária e horária bastante variada. Apesar disso, observa-se que o nitrogênio é o elemento que apresenta maiores concentrações nas amostras analisadas, o que demonstra alta mineralização do material orgânico em suspensão presente no efluente, fato também comprovado pelo alto valor da condutividade elétrica (GUIMARÃES, 2002). Os valores de pH se encontram dentro de uma faixa ideal para o favorecimento da atividade microbiana responsável pela digestão anaeróbia do efluente. De acordo com Sperling (2001) não há inconsistência em se expressar a média aritmética de pH, já que a mesma está diretamente associada a média geométrica da concentração de $\mathrm{H}+$.

Em nenhuma das amostras foi constatada a presença de Salmonella spp., o que atende à portaria n. ${ }^{\circ}$ 451 da Secretaria de Vigilância Sanitária do Ministério da Saúde brasileiro, datada de 19/08/1997 (ANVISA, 1997), onde determina-se que, em hortaliças frescas, refrigeradas ou congeladas, consumidas diretamente, deve haver ausência de Salmonella spp. em 25 gramas de produto. 
Apresentam-se nas Tabelas 2, 3 e 4 os resultados das médias das análises microbiológicas das amostras semanais de solo, água e cultura (realizadas desde a $1^{\mathrm{a}}$ semana após o transplante das mudas até a colheita), para verificar a quantidade de coliformes fecais nos tratamentos T1 a T4.

Analisando-se isoladamente cada tabela, e de acordo com o teste de Kruskal-Wallis, as diferenças dos valores médios entre os tratamentos não foram grandes o suficiente para se excluir a possibilidade de que essas diferenças sejam devido à variabilidade espacial das amostras. Os tratamentos não apresentaram diferenças estatísticas significativas.

Apesar da água utilizada na irrigação não atender à resolução CONAMA 20/86 (BRASIL, 1995), a Secretaria de Vigilância Sanitária do Ministério da Saúde brasileiro aprovou em 19/08/1997 a portaria 451 (ANVISA, 1997) na qual estabelece que, para hortaliças frescas, refrigeradas ou congeladas, consumidas diretamente, deve haver a presença máxima de 200 coliformes fecais por grama. A alface produzida nesse experimento atende a portaria 451, em relação à presença de coliformes fecais.

Apresenta-se na Tabela 5 a comparação dos valores medianos do número mais provável de coliformes fecais, por mililitro, encontrados nas análises microbiológicas, entre os tipos de amostras realizadas (solo dos tratamentos, cultura, água de irrigação em cada tratamento e a água do Ribeirão Lavapés).

Verifica-se que os resultados são maiores do que seria esperado por casualidade, mostrando que há diferença estatística significativa entre os pontos de coleta $(\mathrm{P} \leq 0,001)$. Em relação ao NMP $\mathrm{ml}^{-1}$ de coliformes fecais, as amostras de água de irrigação e do ribeirão não diferiram entre si. Pode-se afirmar, então, que a utilização apenas do filtro de areia não é eficiente na redução do número de coliformes

Tabela 2 - Concentrações de coliformes fecais $\left(\mathrm{NMP} \mathrm{ml}^{-1}\right)$ encontrados nas amostras de solo dos canteiros, realizadas semanalmente. FCA-UNESP, Botucatu-SP, 2002.

\begin{tabular}{ccccc}
\hline Período & Trat 1 & Trat 2 & Trat 3 & Trat 4 \\
\cline { 2 - 5 } (semanas após o transplante) & & Número Mais Provável (NMP) $\mathrm{ml}^{-1}$ & \\
\hline $1^{\text {a } \text { semana }}$ & $2,20 \mathrm{E}+04$ & $1,10 \mathrm{E}+03$ & $4,60 \mathrm{E}+03$ & $2,10 \mathrm{E}+04$ \\
$2^{\mathrm{a}}$ semana & $4,60 \mathrm{E}+01$ & $2,40 \mathrm{E}+02$ & $2,40 \mathrm{E}+02$ & $4,30 \mathrm{E}+01$ \\
$3^{\text {a }}$ semana & $9,00 \mathrm{E}+00$ & $4,00 \mathrm{E}+00$ & $4,00 \mathrm{E}+00$ & $4,00 \mathrm{E}+00$ \\
$4^{\text {a semana }}$ & $4,30 \mathrm{E}+01$ & $1,50 \mathrm{E}+02$ & $2,10 \mathrm{E}+02$ & $4,30 \mathrm{E}+01$ \\
$5^{\text {a }}$ semana & $3,00 \mathrm{E}+00$ & $3,00 \mathrm{E}+00$ & $4,30 \mathrm{E}+01$ & $4,00 \mathrm{E}+00$ \\
$6^{\mathrm{a}}$ semana & $1,50 \mathrm{E}+01$ & $4,30 \mathrm{E}+01$ & $4,00 \mathrm{E}+00$ & $7,00 \mathrm{E}+00$ \\
$7^{\mathrm{a}}$ semana & $1,30 \mathrm{E}+01$ & $9,30 \mathrm{E}+01$ & $2,00 \mathrm{E}+01$ & $2,10 \mathrm{E}+02$ \\
$8^{\text {a semana }}$ & $9,30 \mathrm{E}+01$ & $9,30 \mathrm{E}+01$ & $3,00 \mathrm{E}+00$ & $9,00 \mathrm{E}+00$ \\
\hline
\end{tabular}

Trat $=$ tratamento

Tabela 3 - Concentrações de coliformes fecais (NMP $\mathrm{ml}^{-1}$ ) encontrados nas amostras de água de irrigação em cada tratamento e na água do Ribeirão Lavapés, realizadas semanalmente. FCA-UNESP, Botucatu-SP, 2002.

\begin{tabular}{cccccc}
\hline Período & Trat 1 & Trat 2 & Trat 3 & Trat 4 & Ribeirão Lavapés \\
\cline { 2 - 6 } (semanas após o transplante) & \multicolumn{5}{c}{ Número Mais Provável (NMP) ml ${ }^{-1}$} \\
\hline $1^{\text {a }}$ semana & $2,40 \mathrm{E}+04$ & $4,30 \mathrm{E}+05$ & $4,30 \mathrm{E}+05$ & $1,10 \mathrm{E}+04$ & $4,30 \mathrm{E}+06$ \\
$2^{\mathrm{a}}$ semana & $1,10 \mathrm{E}+06$ & $1,10 \mathrm{E}+06$ & $1,10 \mathrm{E}+06$ & $1,10 \mathrm{E}+06$ & $2,10 \mathrm{E}+06$ \\
$3^{\mathrm{a}}$ semana & $1,50 \mathrm{E}+05$ & $4,60 \mathrm{E}+05$ & $9,30 \mathrm{E}+06$ & $7,50 \mathrm{E}+06$ & $2,40 \mathrm{E}+06$ \\
$4^{\text {a }}$ semana & $4,60 \mathrm{E}+05$ & $2,40 \mathrm{E}+05$ & $1,10 \mathrm{E}+06$ & $1,10 \mathrm{E}+06$ & $4,30 \mathrm{E}+05$ \\
$5^{\text {a }}$ semana & $4,60 \mathrm{E}+05$ & $9,30 \mathrm{E}+05$ & $4,60 \mathrm{E}+06$ & $1,10 \mathrm{E}+07$ & $4,60 \mathrm{E}+06$ \\
$6^{\text {a }}$ semana & $2,40 \mathrm{E}+06$ & $1,50 \mathrm{E}+06$ & $2,40 \mathrm{E}+06$ & $2,40 \mathrm{E}+06$ & $1,10 \mathrm{E}+07$ \\
$7^{\text {a }}$ semana & $1,50 \mathrm{E}+06$ & $4,60 \mathrm{E}+06$ & $4,60 \mathrm{E}+06$ & $9,30 \mathrm{E}+05$ & $2,40 \mathrm{E}+06$ \\
$8^{\text {a }}$ semana & $4,60 \mathrm{E}+06$ & $9,30 \mathrm{E}+05$ & $2,40 \mathrm{E}+06$ & $2,40 \mathrm{E}+06$ & $1,50 \mathrm{E}+06$ \\
\hline
\end{tabular}

Trat $=$ tratamento 
Tabela 4 - Concentrações de coliformes fecais $\left(\mathrm{NMP} \mathrm{ml}^{-1}\right)$ encontrados nas amostras da cultura, realizadas semanalmente. FCA-UNESP, Botucatu-SP, 2002.

\begin{tabular}{|c|c|c|c|c|}
\hline \multirow{2}{*}{$\begin{array}{c}\text { Período } \\
\text { (semanas após o transplante) }\end{array}$} & Trat 1 & Trat 2 & Trat 3 & Trat 4 \\
\hline & \multicolumn{4}{|c|}{ Número Mais Provável (NMP) $\mathrm{ml}^{-1}$} \\
\hline $1^{\mathrm{a}}$ semana & $9,00 \mathrm{E}+00$ & $2,00 \mathrm{E}+01$ & $4,30 \mathrm{E}+01$ & $4,60 \mathrm{E}+01$ \\
\hline $2^{\mathrm{a}}$ semana & $4,30 \mathrm{E}+01$ & $9,30 \mathrm{E}+01$ & $4,30 \mathrm{E}+01$ & $9,00 \mathrm{E}+00$ \\
\hline $3^{\mathrm{a}}$ semana & $4,00 \mathrm{E}+00$ & $3,00 \mathrm{E}+00$ & $4,00 \mathrm{E}+00$ & $3,00 \mathrm{E}+00$ \\
\hline $4^{\mathrm{a}}$ semana & $4,30 \mathrm{E}+01$ & $9,30 \mathrm{E}+01$ & $1,50 \mathrm{E}+02$ & $9,00 \mathrm{E}+00$ \\
\hline $5^{\mathrm{a}}$ semana & $3,00 \mathrm{E}+00$ & $3,00 \mathrm{E}+00$ & $7,00 \mathrm{E}+00$ & $3,00 \mathrm{E}+00$ \\
\hline $6^{\mathrm{a}}$ semana & $4,00 \mathrm{E}+00$ & $4,00 \mathrm{E}+00$ & $4,00 \mathrm{E}+00$ & $4,00 \mathrm{E}+00$ \\
\hline $7^{\mathrm{a}}$ semana & $3,00 \mathrm{E}+00$ & $2,00 \mathrm{E}+01$ & $3,00 \mathrm{E}+00$ & $9,30 \mathrm{E}+01$ \\
\hline $8^{\mathrm{a}}$ semana & $9,30 \mathrm{E}+01$ & $2,10 \mathrm{E}+01$ & $2,10 \mathrm{E}+01$ & $7,00 \mathrm{E}+00$ \\
\hline
\end{tabular}

Trat $=$ tratamento

Tabela 5 - Diferenças nos valores medianos entre os tipos de amostras realizadas (solo dos tratamentos, cultura, água de irrigação em cada tratamento e a água do Ribeirão Lavapés). FCA-UNESP, Botucatu-SP, 2002.

\begin{tabular}{lccc}
\hline \multicolumn{1}{c}{ Tipo de amostra analisada } & Valor da Mediana & $25 \%$ & $75 \%$ \\
\hline Solo do tratamento T1 & $2,90 \mathrm{E}+04 \mathrm{a}$ & $1,10 \mathrm{E}+04$ & $6,95 \mathrm{E}+04$ \\
Solo do tratamento T2 & $9,30 \mathrm{E}+04 \mathrm{a}$ & $2,35 \mathrm{E}+04$ & $1,95 \mathrm{E}+05$ \\
Solo do tratamento T3 & $3,15 \mathrm{E}+04 \mathrm{a}$ & $4,00 \mathrm{E}+03$ & $2,25 \mathrm{E}+05$ \\
Solo do tratamento T4 & $2,60 \mathrm{E}+04 \mathrm{a}$ & $5,50 \mathrm{E}+03$ & $1,27 \mathrm{E}+05$ \\
Alface do tratamento T1 & $6,50 \mathrm{E}+03 \mathrm{a}$ & $3,50 \mathrm{E}+03$ & $4,30 \mathrm{E}+04$ \\
Alface do tratamento T2 & $2,00 \mathrm{E}+04 \mathrm{a}$ & $3,50 \mathrm{E}+03$ & $5,70 \mathrm{E}+04$ \\
Alface do tratamento T3 & $1,40 \mathrm{E}+04 \mathrm{a}$ & $4,00 \mathrm{E}+03$ & $4,30 \mathrm{E}+04$ \\
Alface do tratamento T4 & $8,00 \mathrm{E}+03 \mathrm{a}$ & $3,50 \mathrm{E}+03$ & $2,75 \mathrm{E}+04$ \\
\hline Água de irrigação no tratamento T1 & $7,80 \mathrm{E}+08 \mathrm{~b}$ & $3,05 \mathrm{E}+08$ & $1,95 \mathrm{E}+09$ \\
Água de irrigação no tratamento T2 & $9,30 \mathrm{E}+08 \mathrm{~b}$ & $4,45 \mathrm{E}+08$ & $1,30 \mathrm{E}+09$ \\
Água de irrigação no tratamento T3 & $2,40 \mathrm{E}+09 \mathrm{~b}$ & $1,10 \mathrm{E}+09$ & $4,60 \mathrm{E}+09$ \\
Água de irrigação no tratamento T4 & $1,75 \mathrm{E}+09 \mathrm{~b}$ & $1,02 \mathrm{E}+09$ & $4,95 \mathrm{E}+09$ \\
\hline Água do Ribeirão Lavapés & $2,40 \mathrm{E}+09 \mathrm{~b}$ & $1,80 \mathrm{E}+09$ & $4,45 \mathrm{E}+09$ \\
\hline
\end{tabular}

fecais, pois tanto as amostras de água coletadas no ribeirão como as situadas após o sistema de filtragem na saída das mangueiras de irrigação (T1, T2, T3 e T4) apresentaram altas quantidades de coliformes fecais (Tabela 2).

As amostras de água diferiram significativamente das de solo e da alface em todos os tratamentos. Observouse também que as amostras da cultura e de solo apresentaram baixas quantidades de coliformes fecais (Tabelas 1 e 3) quando comparadas com as amostras da água (Tabela 2). Isso pode ser explicado pelo fato do sistema de irrigação por gotejamento molhar apenas o volume de solo compreendido pelas raízes das plantas, não existindo então o contato direto da água de irrigação com a alface, e pelo fato de ter ocorrido um período de 24 horas entre a última irrigação e a colheita da planta.

Corroborando essa explicação está a afirmação de Paganini (1997), que cita que nos sistemas de disposição por irrigação em solos de textura fina, a remoção de bactérias e parasitas é alta $(99,9 \%)$ e acontece quase que completamente nos primeiros $150 \mathrm{~cm}$ de profundidade. Também, segundo o autor, $90 \%$ das bactérias são eliminadas durante as primeiras 48 horas após a irrigação e a quantidade remanescente durante as duas semanas seguintes.

Nas amostras analisadas não foi encontrada a presença de formas evolutivas de parasitos humanos 
(cistos de protozoários e ovos de helmintos), porém, foram detectados ovos e larvas de nematódeos não parasitos humanos. Não se realizaram a identificação das espécies de nematódeos encontrados com base na morfologia das larvas e/ou ovos devido o elevado custo requerido para a grande quantidade de amostras necessárias. Apesar disso, a morfologia dessas formas evolutivas foram suficientes para excluir a possibilidade de serem parasitos humanos. As larvas e ovos podem ser nematódeos de vida livre ou parasita de outros animais (anfíbios, répteis, aves ou mamíferos) que tiveram contato com o solo. Apresenta-se na Tabela 6 o valor médio das frequiências com que foram encontrados larvas e ovos de parasitos nas amostras realizadas, durante o decorrer do ciclo da cultura.

Apesar das larvas e ovos encontrados nas amostras desse experimento não se tratarem de parasitos não humanos, as mesmas podem vir a gerar quadros de larva migrans cutânea, caracterizados pela sua penetração nos tecidos cutâneos de um indivíduo e como não encontra condições apropriadas para seu desenvolvimento, pois o homem não é o seu hospedeiro normal, morre em pouco tempo. Por isso, apesar da alface produzida nesse experimento atender à portaria 451, como já foi dito anteriormente, a água que foi utilizada na irrigação não atende à recomendação da Organização Mundial de Saúde (OMS) que determina menos de um ovo de nematóide, por litro (SILVA, 2003), e o consumo da alface não pode, portanto, ser recomendado.

Podemos concluir que a disposição das mangueiras gotejadoras sobre os canteiros, a desinfecção com cloro e o uso do sistema de filtragem convencional não alteram de forma expressiva a quantidade de microrganismos na água de irrigação. Em relação apenas à presença de coliformes fecais, o consumo da alface produzida nesse experimento poderia ser possível, após ser desinfetada com solução clorada, por atender às exigências da Secretaria de Vigilância Sanitária do Ministério da Saúde brasileiro (portaria no 451 de 19/08/1997). Porém como foi detectada a presença de nematóides, em quantidades superiores ao permitido pela Organização Mundial de Saúde (OMS), sua utilização não é apropriada para o consumo humano.

\section{REFERÊNCIAS BIBLIOGRÁFICAS}

AGÊNCIA NACIONAL DE VIGILÂNCIA SANITÁRIA. Portaria 451, de 22 de setembro de 1997. Diário Oficial da União, Brasília, n. 182, p. 21005-21012, 1997. Seção 1.

BASTOS, R. K. X.; MARA, D. D. Avaliação dos critérios e padrões de qualidade microbiológica de esgotos sanitários tendo em vista sua utilização na agricultura. In: CONGRESSO BRASILEIRO DE ENGENHARIA SANITÁRIA E AMBIENTAL, 17., 1993, Natal, RN. Anais... Natal: UFRN, 1993.

BLUNDI, C. E. Aplicação de métodos alternativos para determinação de matéria orgânica e biomassa em águas residuárias. 1988. 229 f. Tese (Doutorado) - Universidade Federal de São Carlos, São Carlos, 1988.

BRASIL. Controle da poluição ambiental. São Paulo: CETESB, 1995. 213 p. (Série documentos).

CASTRO DE ESPARZA, M. L.; SÁENZ, R. F. Evaluación de riegos para la salud por el uso de aguas residuales en agricultura: aspectos microbiológicos. Lima: Cepis, 1990.

CONAMA. Resoluções do conselho nacional do meio ambiente, leis, etc: 1984/86. 2. ed. Brasília, DF: Sema, 1998. $98 \mathrm{p}$.

CONTE, M. L. Espécies químicas dissolvidas no Ribeirão Lavapés, Botucatu-SP. 1992. 128 f. Dissertação (Mestrado em Agronomia/Energia na Agricultura) - Universidade Estadual Paulista, Botucatu, 1992.

Tabela 6 - Valores médios do percentual de amostras indicativas da presença de larvas e ovos de parasitos. FCAUNESP, Botucatu-SP, 2002.

\begin{tabular}{lcccc}
\hline \multicolumn{1}{c}{ Amostras } & \multicolumn{4}{c}{ Percentual indicativo } \\
\hline Ribeirão Lavapés & $\mathrm{O}$ & $\mathrm{L}$ & $\mathrm{O} / \mathrm{L}$ & n.e. \\
Água de irrigação & --- & $37,50 \%$ & $12,50 \%$ & $50,00 \%$ \\
Solo & $9,38 \%$ & $40,63 \%$ & $18,75 \%$ & $31,25 \%$ \\
Cultura & $6,25 \%$ & $31,25 \%$ & $31,25 \%$ & $31,25 \%$ \\
\hline
\end{tabular}

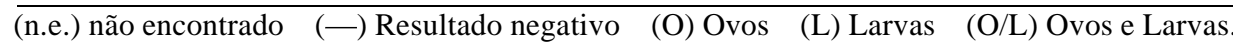


CUNHA, A. R. et al. Classificação climática para o município de Botucatu, SP, segundo Köppen. In: SIMPÓSIO EM ENERGIA NA AGRICULTURA, 1., 1999, Botucatu. Anais... Botucatu: UNESP-FCA, 1999. p. 487-491.

DOWNES, F. P.; ITO, K. (Eds.). Compendium of methods for the microbiological examination of foods. Washington: Apha, 2001.

GUIMARÃES, A. B. Reator anaeróbio horizontal de leito fixo (RAHLF) combinado com sistema fito-pedológico aplicado ao tratamento de esgotos sanitários. 2002. 119 f. Dissertação (Mestrado em Agronomia/Energia na Agricultura) Universidade Estadual Paulista, Botucatu, 2002.

HARUVY, N. Agricultural reuse of wastewater: nation-wide cost-benefit analysis agricultural. Ecossytems and Environment, Elselvier, v. 66, p. 113-119, 1997.

KORNACKI, J. L.; JOHNSON, J. L. Enterobacteriaceae, coliforms, and Escherichia coli as quality and safety indicators. In: COMPENDIUM OF METHODS FOR THE MICROBIOLOGICAL EXAMINATION OF FOODS, 2001, Washington, DC. Proceedings... Washington: Apha, 2001. p. $69-80$.

LEAL, M. A. de A.; PENTEADO, A. de F. Eficiência dos métodos não-paramétricos sobre a capacidade de nodulação em leguminosas. Revista Pesquisa Agropecuária Brasileira, Brasília, v. 29, n. 2, 1994.

LÉON, S. G.; CAVALLINI, J. M. Curso de tratamento y uso aguas residuales. Lima: OPS/CEPIS, 1996. 151 p.

LEOPOLDO, P. R. Aspectos hidrológicos da região de Botucatu. In: ENCONTRO DE ESTUDOS SOBRE AGROPECUÁRIA NA REGIÃO DE BOTUCATU, 1989, Botucatu. Anais... Botucatu: Unesp, 1989. p. 57-70.
LOPES-FLORES, R. et al. Comparison of nutrient and contaminant fluxes in two areas with different hydrological regimes (Emporda Wetlands, NE Spain). Water Research, Amsterdam, v. 37, p. 3034-3046, 2003.

MACIEL, C. F. Migração ascendente no solo de larvas infectantes de nematóides gastrointestinais de ovinos. 1984. 69 f. Dissertação (Mestrado) - Universidade Federal do Rio Grande do Sul, Porto Alegre, 1984.

MELO, J. A. S. Aplicação de águas residuárias no solo como um método de tratamento, disposição final e reciclagem das águas usadas. Revista de Engenharia Sanitária, [S.1.], v. 17, p. 82-91, 1978.

NEVES, D. P. Parasitologia humana. Rio de Janeiro: Atheneu, 2000. 428 p.

PAGANINI, W. S. Disposição de esgotos no solo: escoamento à superfície. São Paulo: AESABESP, 1997. 232 p.

PICARÓ, P.; PERLOIRO, F. A evidência da intervenção precoce da fisioterapia em mulheres mastectomizadas: estudo comparativo. EssFisiOnline, [S.1.], v. 1, n. 2, mar. 2005.

REY, L. Parasitologia. Rio de Janeiro: Guanabara Koogan, 1991. $731 \mathrm{p}$.

SILVA, V. de P. Águas servidas: uma alternativa viável. Disponível em: <http://www.ufrpe.br/artigos/artigo02.html>. Acesso em: 1 dez. 2003.

SPERLING, M. Coliformes e pH-médias aritméticas, médias geométricas e medianas. In: CONGRESSO BRASILEIRO DE ENGENHARIA SANITÁRIA E AMBIENTAL, 21., 2001, João Pessoa. Resumos... João Pessoa: ABES, 2001. p. 76. 